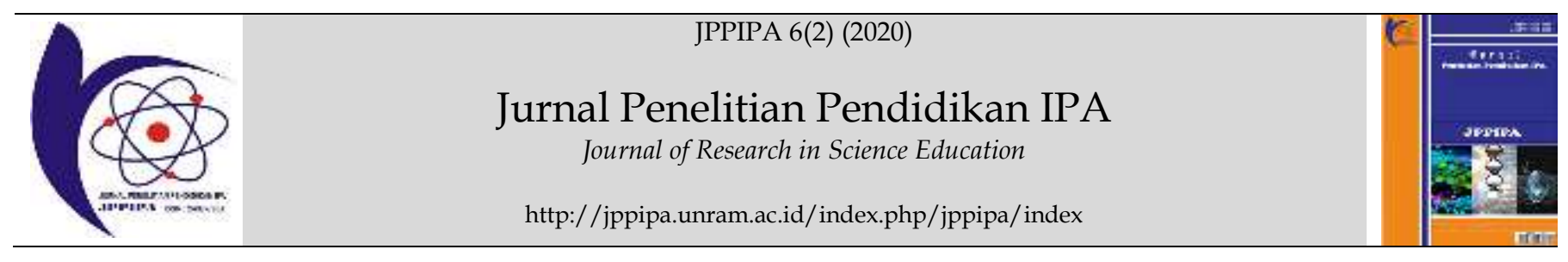

\title{
Colonisation Capacity of Vibrio sp. strain Alg 3.1 and Abn 1.2 in the Gastrointestinal Tractof Gnotobiotic Abalone
}

\author{
Faturrahman ${ }^{1 *}$, Iman Rusmana ${ }^{2}$ dan Anja Meryandini ${ }^{2}$ \\ ${ }^{1}$ Department of Biology, Faculty of Mathematics and Natural Sciences, Mataram University, Jl.Majapahit 62, Mataram 83125, West Nusa \\ Tenggara, Indonesia. \\ 2Department of Biology, Faculty of Mathematics and Natural Sciences, Bogor Agricultural University Darmaga, Bogor 16680 West Java, \\ Indonesia
}

\section{DOI: $10.29303 /$ ippipa.v6i2.339}

\section{Article Info}

Received: November 18st, 2019

Revised: March 27st, 2020

Accepted: June 15st, 2020

\begin{abstract}
The use of Vibrio strains as probiotics in Indonesia is very rarely reported. The purpose of this study is to select and develop Vibrio probiotic strains that can increase the rate of abalone growth. The ability of bacterial isolates to colonize the abalone digestive tract is one of the important parameters in the selection of probiotic candidates. The research method consisted of 3 main stages namely modification of Vibrio sp isolates to rifampicin mutants, manufacture of gnotobiotic abalone and colonization capacity test. The treatment given in the colonization capacity test is a type of bacteria that consists of Vibrio sp. line Abn1.2RfR, Alg3.1RfR, combination of Abn1.2RfR + Alg3.1RfR, and control without the addition of Vibrio sp. Each type of bacterial treatment was entered in a 10 liter aquarium capacity containing 10 abalone size $\pm 3.5 \mathrm{~cm}$. Feed in the form of Gracilaria cake containing Vibrio sp. (final concentration of $10^{7} \mathrm{cfu} / \mathrm{mL}$ ) was given at the beginning of the study. Abalone is observed for 24,48 and 72 hours without water replacement. Then count the total number of bacteria and the number of agarolytic bacteria. The results showed that the growth characteristics of wild-type Vibrio with mutant Vibrio were not different.Thus it is expected that the use of the two mutant isolates for in vivo testing has the same effectiveness as the wild type. The capacity of colonization of a single isolate or a combination of rifampicin mutant Vibrio continues to decrease with increasing time of observation. Nevertheless, the percentage of mixed isolates remained higher than that of single isolates during the observation time.
\end{abstract}

Keywords: Colonization; Vibrio, abalone; cake; Gracilaria.

Citation: $\quad$ Faturrahman., Rusmana, I., Meryandini, A. (2020). Colonisation Capacity of Vibrio sp. strain Alg 3.1 and Abn 1.2 in the Gastrointestinal Tractof Gnotobiotic Abalone. Jurnal Penelitian Pendidikan IPA (JPPIPA), 6(2), 173-177. doi: https://doi.org/10.29303/jppipa.v6i2.339

\section{Introduction}

Among marine bacteria, Vibrio is an important producer of antibiotics. Inhibitor compounds produced by certain Vibrio isolates can reduce other community members such as Alfa-proteobacteria and Alteromonas (Lin et al, 2018). This genus plays an important role in the nutritional cycle in aquatic environments through the breakdown of organic matter. Vibrio provides polyunsaturated fatty acids (Estupinan et al, 2020) which are essential for the aquatic food chain, which many of the aquatic organisms are unable to produce. In addition, Vibrio can also degrade chitin (Hayes et al, 2017), a homopolymer of GlcNAc, is a structural material in many invertebrates, bacteria, fungi and algae (Yadav et al, 2011).

Utilization of Vibrio strains as probiotics has been widely reported. The reason for its use is because 
this bacterial group has a number of characters needed by a probiotic (Ortiz-Carillo et al, 2015) in an aquaculture system, including being able to compete with other bacteria (Thompson et al, 2010), add nutrition by providing essential nutrients, can improve digestibility by releasing essential enzymes (Lin et al, 2018) has the ability to colonize the digestive tract and host body (Gomez-Gil et al, 2014), and can produce substances that inhibit the growth of opportunistic pathogenic bacteria (Pereire et al, 2018).

A strain of bacteria can be functional as a probiotic if it has a high capacity to be able to live and colonize the digestive tract of organisms under various conditions of the aquatic environment. In this study a capacity test for the colonization of Vibrio spp Abn1.2 and Alg3.1 strains in the digestive tract of the gnotobiotic abalone was carried out.

\section{Method}

Preparation of Bacteria Culture. Bacterial isolate that was used to test the ability of colonization was Vibrio sp. strain Abn1.2 and Alg3.1. Bacterial isolates were grown on SWM broth medium and incubated at $29{ }^{\circ} \mathrm{C}$ while shaken 120 revolutions per minute. Then the final concentration is adjusted to $10^{8} \mathrm{cfu} / \mathrm{ml}$.

Preparation of Test Animals. Abalone used in this study came from the hatchery and production unit of the Lombok Sea Aquaculture Center. The procedure for preparing experimental animals is as follows: Abalone is maintained at $26-28{ }^{\circ} \mathrm{C}$ in a polyethylene tank containing $98 \mathrm{~L}$ of seawater which is filtered and aerated continuously. The abalone is acclimatized for 2 weeks before being used for research, during this process the abalone is only fed Gracilaria sp. cake.

Making Rifampicin-resistant Mutants.The manufacture of rifampicin mutants was carried out as follows: Approximately $10^{8} \mathrm{cfu} / \mathrm{mL}$ isolates of Alg3.1 and Abn1.2 stationary phases were grown on MA medium containing $50 \mu \mathrm{g} / \mathrm{mL}$ rifampicin, then as many as 15 colonies that grew were re-bottled on MA medium containing $100 \mu \mathrm{g} / \mathrm{mLrifampicin.} \mathrm{These}$ rifampicin-resistant Alg3.1 and Abn1.2 isolates were evaluated qualitatively for their growth rate and enzyme activity.

Preparation of the Gnotobiotic Abalone. Gnotobiotic abalone is an abalone that does not contain bacteria outside the body or digestive tract. The manufacture of gnotobiotic abalone was carried out as follows: Before the experiment was carried out all equipment was disinfected with a 50-100 ppm chlorine solution. Furthermore, as many as 6 aquariums (10 liters) are used as a maintenance container and channel seawater and air filter stones at a constantrate (400 $\mathrm{mL} / \mathrm{min}$ ). The equipment used for sample collection is sterilized with $95 \%$ ethanol. Inside each aquarium is filled with 12 abalones. Then the abalone is given antibiotic treatment to reduce enteric bacteria in the digestive tract by means of abalone fasted for 2 days then given food containing antibiotics for 4 days. After the first 2 days the water flow is stopped for 24 hours and antibiotics are inserted (ampicillin, $500 \mathrm{mg} / \mathrm{L}$, rifampicin $125 \mathrm{mg} / \mathrm{L}$, and chloramphenicol, $250 \mathrm{mg} /$ L). The next day antibiotics were added again for 24 hours and were still fed with antibiotics (rifampicin 100 $\mu \mathrm{g} / \mathrm{mL}$ ). After 24 hours of treatment, the aquarium water is replaced with new water.

Colonization Capability Test. The ability of colonization of probiotic candidate isolates was carried out according to following method: before testing, all equipment used was disinfected with $70 \%$ ethanol. The study design was a randomized complete design with 4 treatments and 2 replications for each treatment. The treatment given is the type of bacteria that consists of Abn1.2RfR, Alg3.1RfR, a combination of Abn1.2Rf $f^{R}+$ Alg3.1RfR, and control without the addition of probiotic bacteria. Each type of bacterial treatment was entered in a 10 liter aquarium capacity containing 10 abalone size $\pm 3.5 \mathrm{~cm}$ Feed in the form of Gracilaria cake containing agarolytic bacteria (final concentration of $10^{7}$ cfu / $\mathrm{mL}$ ) was given at the beginning of the study. Abalone is observed for 24,48 and 72 hours without water replacement.

Then the total bacterial count and the number of agarolytic bacteria were calculated. For the isolation of agarolytic isolates, abalone digestive tract in the form of hepatopancreas, stomach and intestine was taken, homogenized and made 6 series of dilutions $(1 / 10)$. The suspension was held for MA media ( $2 \%$ agar, $2 \%$ $\mathrm{NaCl}$ and $100 \mu \mathrm{g} / \mathrm{mL}$ rifampicin) using scatter plates and incubated at $29^{\circ} \mathrm{C}$ for 24 hours. The percentage of colonization was evaluated by calculating the $\mathrm{CFU} / \mathrm{g}$ sample.

\section{Result and Discussion}

Properties of Vibrio sp. Rifampicin-resistant mutants. In vivo probiotic bacteria testing in an environment that is not free of bacteria makes it difficult to evaluate or re-isolate the test bacteria. One strategy that can be used is to make mutant probiotic bacteria. A marker commonly used for spontaneous mutations is antibiotic resistance. In this study rifampicin antibiotics are used because according to Aprilasari et al, (2016) that marine bacteria are generally sensitive to rifampicin. These rifampicinresistant Alg3.1 and Abn1.2 isolates were evaluated qualitatively for growth rate and enzyme activity (Figure 1 and Table 1). 

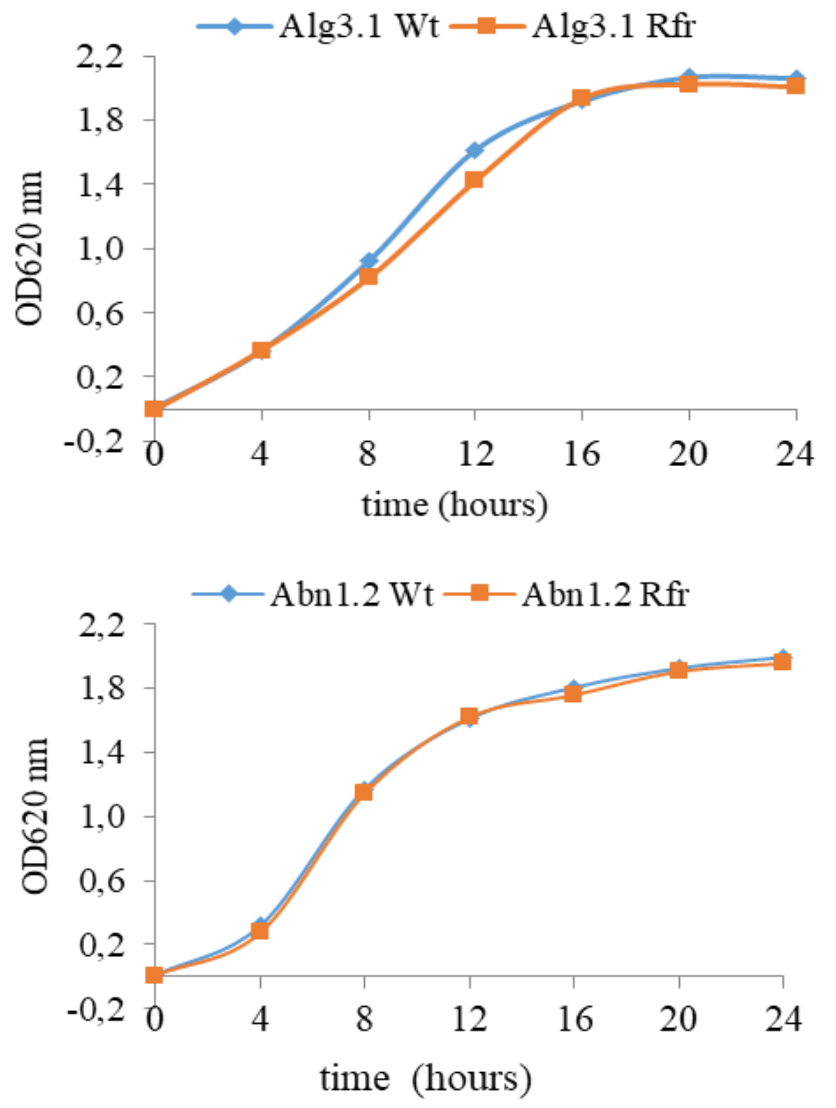

Figure 1. Comparison of growth curves of wild type isolates of Alg3.1 and Abn1.2 bacteria with rifampicin mutants

Figure 1 shows that there is no difference in the growth rate of wild type of the two isolates with their rifampicin mutants, although it is known that rifampicin antibiotics are RNA polymerase inhibitors so that they can inhibit mRNA synthesis. This means that spontaneous mutations that occur do not interfere with the function of this enzyme.Furthermore, the ability of the wild type of the two isolates with their mutant type to produce agarase enzymes was tested qualitatively by measuring the diameter of the clear zone formed (Table 1).

Table 1. Qualitative agarase activities between wild type and mutant isolates Alg3.1 and Abn1.2

\begin{tabular}{llll}
\multirow{2}{*}{ No } & Isolates & \multicolumn{2}{c}{$\begin{array}{l}\text { Diameter of clearing zona } \\
\text { (mm) }\end{array}$} \\
\cline { 3 - 4 } & & 24 hour & 48 hour \\
\hline 1 & Abn1.2 Wt & 20.75 & 27.50 \\
2 & Abn1.2 Rfr & 20.25 & 28.25 \\
3 & Alg3.1 Wt & 27.50 & 33.25 \\
4 & Alg3.1Rfr & 27.25 & 32.75 \\
5 & $1+3 \mathrm{Wt}$ & 34.25 & 45.25 \\
6 & $2+4 \mathrm{Rfr}$ & 33.75 & 44.25 \\
\hline
\end{tabular}

The results of the analysis by $t$ test showed that the qualitative agarase activity of isolates Alg3.1 and Abn1.2 in hydrolyzing agar in the form of single culture or mixed culture was not significantly different $(\mathrm{P}<0.05)$ with the mutant type, thus it was hoped that the use of both mutant isolates for testing in vivo has the same effectiveness as the wild type.
Colonization
Capability.
Colonization experiments were carried out to measure the capacity of a bacterial strain to live, grow and colonize its host digestive tract. A probiotic can provide benefits in providing essential nutrients and enzymatic contribution to its host if the probiotic is able to properly colonize the host digestive tract.

Consistently the combination of Alg3.1-RfR and Abn1.2-RfR shows a higher population than when introduced in the form of a single isolate (Table 2), whereas Alg3.1-R $\mathrm{f}^{\mathrm{R}}$ has the lowest population at 24, 48 or 72 hours observation.

Table 2. Total bacteria Alg3.1-RfR, Abn1.2-RfR, combination and control $(\log 10 \mathrm{cfu} / \mathrm{ml})$ in the abalone digestive tract for 24-72 hours of observation

\begin{tabular}{llll}
\hline Isolates & \multicolumn{3}{l}{ Incubationtimes (hour) } \\
\cline { 2 - 4 } & 24 & 48 & 72 \\
\hline Alg3.1 & 7.45 & 7.06 & 6.58 \\
Abn1.2 & 7.60 & 7.39 & 7.07 \\
Mix & 7.66 & 7.55 & 7.25 \\
control & 7.73 & 7.72 & 7.70 \\
\hline
\end{tabular}

The ability of colonization of a single isolate and its combination continued to decrease with increasing observation time (Figure 2). Nevertheless the percentage of mixed isolates remained higher than that of single isolates during the observation time.

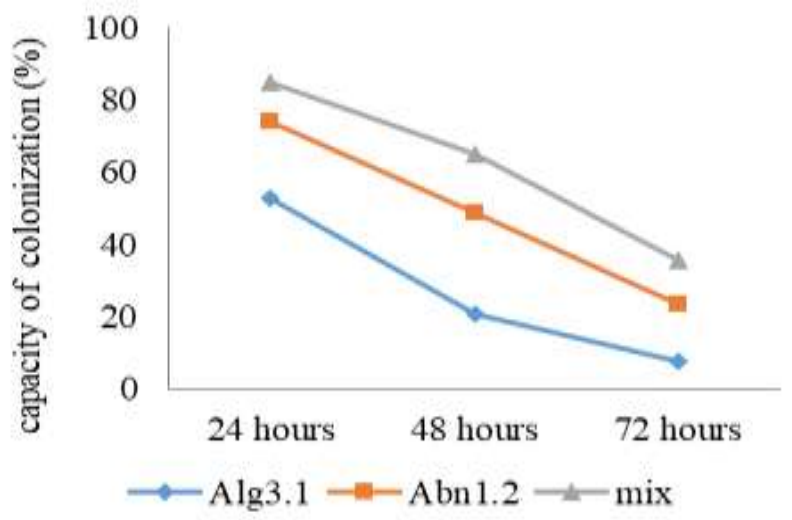

Figure 2. The ability of colonization of bacterial isolates Alg3.1-RfR, Abn1.2-RfR, mix and control in the abalone digestive tract for 72 hours of observation

The percentage of mixed culture colonization was still above $50 \%$ at 48 hours of observation, while single culture remained $21.81 \%$ for $\operatorname{Alg} 3.1-\mathrm{Rf}^{\mathrm{R}}$ and $48.22 \%$ for Abn1.2-RfR. After 72 hours of observation, the percentage of colonization of isolates both single and the combination was left with $7.58 \%$ for Alg3.1-RfR, 
21.85\% for Abn1.2-RfR, and 33.67\% for mixed isolates. Decrease in the concentration of probiotic bacteria in the digestive tract can take place some time since probiotics are given this happens because the digestive tract of marine animals constantly in contact with their environment so that it can be eroded with sea water and come out together with feces. According to Behnsen et al, (2013), the characteristic of probiotic microbes is its ability to colonize the digestive tract of the host, but the intestinal tract microbiota in aquatic animals changes rapidly because it is constantly related to the flow of microbes originating from water and food.

The results of research by Iehata et al, (2010) also showed a decrease in the population of Pediococcus sp. Ab1 was significant in the Haliotis gigantea digestive tract since the first day of observation. While Afrilasari et al, (2016) stated that the number of probiotic cells successfully isolated from catfish after administration of probiotics for 30 days ranged from $2 \times 10^{5}$ $5 \times 10^{7} \mathrm{cfu} / \mathrm{g}$, where there was a significant decrease in the number of probes after days after administration.

In contrast to humans and terrestrial animals, the existence of microorganisms in the digestive tract of aquatic organisms does not exist as a separate entity, but is constantly related to microorganisms in their environment. Therefore the presence of bacteria in the aquatic environment affects the composition of microbiota in the digestive tract and vice versa (Sayes et al, 2018).

This data of colonization capacity can be used as a basis for selecting isolates and the frequency of probiotic administration during application to abalone feed. Based on this data, the provision of probiotics is done every 3 days in the form of a mix culture. Huddy and Coyne (2014) suggest that if there is a significant decrease in the number of probes after 2 days of probiotic administration, to maximize the benefits for the host it is necessary to supplement probiotics once every two days.

\section{Conclusion}

The nature of wild type Vibrio with mutant vibrio is not significantly different so it is expected that the use of the two mutant isolates for testing in vivo has the same effectiveness as the wild type. The capacity of colonization of a single isolate or a combination of rifampicin mutant Vibrio continues to decrease with increasing time of observation. Nevertheless, the percentage of mixed isolates remained higher than that of single isolates during the observation time. Provision of probiotic bacteria needs to be done periodically to minimize the loss of probiotics from the abalone digestive tract.

\section{References}

Afrilasari, W., Widanarni., Meryandini, A. (2016). Effect of Probiotic Bacillus megaterium PTB 1.4 on the Population of Intestinal Microflora, Digestive Enzyme Activity and the Growth of Catfish (Clarias sp.). HAYATI Journal of Biosciences. 23 (4), 4168-172. doi.org/10.1016/j.hjb.2016.12.005

Behnsen, J., Deriu, E., Sasonne-Corsi, M., \& Rafatellu, M. (2013). Probiotics: Properties, Examples, and Specific Applications. Cold Spring Harbor Perspect Med 3: 1-15. doi: 10.1101/cshperspect.a010074

Estupinan, M,I., Hernandez, E., Saitua, M.E., Bilbao, I., Mendibil, J., Ferrer, L., \& Alonzo-Saez. (2020). Novel Vibrio spp. Strains Producing Omega-3 Fatty Acids Isolated from Coastal Seawater. Mar. Drugs (18) 99. 1-15. doi: $10.3390 / \mathrm{md} 18020099$

Gomez-Gil, B., Thompson, C.C.Y. Matsumura, T. Sawabe, T. Iida, R. Christen, et al. (2014). Family Vibrionaceae (Chapter 225), in The Prokaryotes, 4th Edn., eds Rosenberg E., DeLong E. F., Thonpson F. L., Lory S., Stackebrandt E. New York, NY: Springer.

Hayes, C.A., Dalia, T.N., \& Dalia, A.B. (2013). Systematic genetic dissection of chitin degradation and uptake in Vibrio cholerae. Environ Microbiol. 19(10): 4154-4163. doi: $\underline{10.1111 / 1462-2920.13866}$

Huddy, R.J \& Coyne, V.E. (2014). Detection and Localisation of the Abalone Probiotic Vibrio midae SY9 and Its Extracellular Protease, VmproA, within the Digestive Tract of the South African Abalone, Haliotis midae. Plos One, 9(1):1-9. DOI: 10.1371/journal.pone. 0086623

Iehata, S., Inagaki, T., Okunishi, S., Nakano, M., Tanaka, R., \& Maeda, H (2010). Improved gut environment of abalone Haliotis gigantea through Pediacoccus sp. Ab1 treatment. Aquaculture 305: 59-65.

doi: https://doi.org/10.1016/j.aquaculture.2010.04.0 $\underline{12}$

Lin, H., Yu, M., Wang, X., \& Zhang, X-H. (2018). Comparative genomic analysis reveals the evolution and environmental adaptation strategies of vibrios. BMC Genomics, 19 (135). Doi: https://doi.org/10.1186/s12864-018-4531-2

Ortiz-Carillo, I., Estrella-Gomez, N.E., Zamudio-Maya, M., \& Rojas-Herrera, R. (2015). Diversity of Vibrio spp in Karstic Coastal Marshes in the Yucatan Peninsula. Plos ONE, 1-14. doi: https://doi.org/10.1371/journal.pone.0134953

Pereira, G.V.M., Coelho, B.O., Junior, A.I.M., ThomasSoccol, V., Soccol, C.R. (2018). How to select a probiotic? A review and update of methods and 
criteria. Biotechnol Adv. 36(8):2060-2076. doi: 10.1016/j.biotechadv.2018.09.003

Sayes, C., Leyton, Y., \& Riquelme, C. (2018). Probiotic Bacteria as an Healthy Alternative for Fish Aquaculture. Intech. 115-132.

Thompson, J., Gregory, S., Plummer, S., Shields, R.J., \& Rowley. A.F. (2010). An in Vitro and in Vivo Assessment of the Potential of Vibrio Spp. As Probiotics for the Pacific White Shrimp. Litopenaeus Vannamei. J Appl Microbiol 109(4): 1177-87. doi: 10.1111/j.1365-2672.2010.04743.x

Yadav, V., Panilaitis, B., Shi, H., Numuta, K., Lee, K., \& Kaplan, D.L. (2011). N-acetylglucosamine 6Phosphate Deacetylase (nagA) Is Required for Nacetyl Glucosamine Assimilation in Gluconacetobacter xylinus. Plos ONE 6 (6):1-11. doi: 10.1371/journal.pone.0018099 